\title{
Upgrading a ColdFusion-Based Academic Medical Library Staff Intranet
}

Robert Vander Hart

Electronic Resources Librarian

robert.vanderhart@umassmed.edu

Barbara Ingrassia

Associate Director, Strategic Initiatives and Work Force Development

Kerry Mayotte

Public Desk Supervisor, Library Operations

Lisa A. Palmer

Institutional Repository Librarian

Julia Powell

Library Assistant

University of Massachusetts Medical School

Lamar Soutter Library

55 Lake Avenue North

Worcester, MA 01655

\section{Abstract}

This article details the process of upgrading and expanding an existing academic medical library intranet to include a wiki, blog, discussion forum, and photo collection manager. The first version of the library's intranet from early 2002 was powered by ColdFusion software and existed primarily to allow staff members to author and store minutes of library team meetings. Other ColdFusion-based applications and functions were subsequently added, as were various other library documents and procedures. As a follow-up to the library's strategic plan, a library Staff Intranet Team was organized in early 2008 to reorganize the content of the intranet and to identify software tools that would allow greater staff participation in maintaining and updating intranet content. Early steps in the process included brainstorming, a card-sorting exercise, product research, a staff survey, and paper prototyping. The team focused on implementing various open-source ColdFusion-based tools in order to align with existing technology, available budget, and time constraints. Challenges in implementing the tools 
included bypassing or modifying existing authentication systems, and applying modifications that led to loss of native functionality. Despite usability testing and staff training, library staff have not universally welcomed or adopted all the new tools to date. Notwithstanding these challenges, the renovated staff intranet has shown promise in furthering goals in the library's strategic plan to improve communication and facilitate collaboration among library staff.

Keywords: Libraries, Intranets, ColdFusion, Wikis, Blogs, Discussion Forums, Photo Collection, Training, Evaluation

\section{Introduction}

Many organizations and institutions, whether for-profit, non-profit, or educational, make use of intranets for increased staff productivity. Intranets have evolved from unidirectional information channels between managers and employees to integrated workspaces that support collaboration, communication, daily operations, and information needs of staff (Martini, Corso, and Pellegrini 2009, 295-308). Tools such as wikis, blogs and discussion forums on intranets enable greater opportunities for staff collaboration. Skills such as blogging, maintaining a wiki, and uploading and tagging photos may be vital for library staff to possess in order to meet the evolving needs of both themselves and their patrons.

The University of Massachusetts Medical School, which opened in 1970, includes the graduate schools of medicine, nursing, and biomedical sciences. The Lamar Soutter Library, which is open to the public, is considered a medium-sized academic health sciences library. The library staff consists of almost 40 FTE and serves more than 1100 students, 1300 faculty, and thousands of additional researchers, clinicians, and employees.

Discussions about an intranet at the library began in 1999 and came to fruition in early 2002. At that time, the intranet was conceived as a repository for library teams and departments to author, edit, and retrieve meeting minutes and to archive reports. Several Web forms, developed by the library Web manager, facilitated the management of meeting minutes by library staff. Other new content, however, had to be added by the Web manager. 
The intranet is hosted on a library-owned Web server running the Linux operating system. It is maintained by library staff members and powered by ColdFusion software from Adobe Systems Incorporated (http://www.adobe.com/products/coldfusion/). Library interest in ColdFusion stemmed from the University's decision in the late 1990s to utilize the software for its own Web site. Advantages of ColdFusion include easy application development, a low learning curve, and a simple tag-based language. The major disadvantage is the cost of the software (Langley 2007).

As a follow-up to the library's 2006 Strategic Plan (Lamar Soutter Library, University of Massachusetts Medical School 2006), a cross-departmental intranet team was formed in early 2008. By this time the library's intranet had outgrown its original conception and was hosting several locally developed ColdFusion-based applications necessary for some staff members to perform their duties. The Staff Intranet Team was charged to "identify content, a new organization and potential tools (open source) to improve the functionality and ongoing maintenance (perhaps self-service) of the staff intranet" (Lamar Soutter Library, University of Massachusetts Medical School 2009b).

The team thus had two main tasks: to reorganize the content of the intranet and to identify software tools that would allow greater staff participation in maintaining and updating intranet content. The team charge addressed several goals and objectives in the library's Strategic Plan:

- Overcome departmental barriers within the library that limit service to our patrons

o Share knowledge among library departments through integrated documentation in order to understand the best department to provide service.

o Establish a central repository of current and archived library-wide policies and procedures.

- Improve intra- and cross-departmental communication so that all library departments can operate interdependently to improve the quality, quantity, and speed of information provided internally.

o Communicate to all staff new products and services at the library.

o Explore and implement opportunities to share expertise across departments such as 
short term assignments for a particular task or project.

o Provide new ways for staff to provide input on new and/or old services, policies, procedures and how they can be improved.

- Foster an environment within the library conducive to collaboration.

o Explore ways library staff can actively participate in collaborative efforts.

Team members also hoped that, as a result of their efforts, usage of the intranet would increase, and that a greater community atmosphere in the library would be cultivated by incorporating collaborative tools.

\section{Literature Review}

In their 2007 book, Mary Lee Kennedy and Jane Dysart $(2007,17)$ observed that

There are an enormous number of technology choices to be made when looking at intranet applications, and custom-built applications continue to be a popular choice for many organizations. These choices can fluctuate depending on resident expertise, strength of senior sponsorship, technology integration costs, sophistication of user expectations, and (of course) available budget.

Very little has been published in the library and information science literature about the use of ColdFusion as a technology choice for intranet applications. However, the published literature is rich with articles about intranets - their various uses and components, and the process for developing them through the various and often inter-related phases of investigating, needs assessment, implementing, testing, promoting, training, adding and updating content, day-today oversight, and ongoing evaluation and revision.

Several articles were particularly helpful in informing the team's thinking as the project moved through its phases. Mel O'Brien and Jillian Wisbey $(2008,29)$ focused on what they called the "soft aspect" of the intranet: the "planning, implementation, management, evaluation...and integration...rather than the hard equipment and technological aspects." They offered helpful, specific suggestions for training, evaluation, promotion, marketing, and for dealing with issues and challenges. They emphasized the importance of the four elements: people, process, content, and technology. In addition, Darlene Fichter (Fichter 2006, 46-48; Fichter 2006, 51-53; 
Fichter 2005, 47-50; Fichter 2008, 55-57) offers specific ideas for designing effective intranets in her "Intranet Librarian" column in ONLINE.

Joel Glogowski and Sarah Steiner $(2008,87-98)$ provided a brief general overview of wikis, pointing out that they are "an ideal tool for online collaboration" and help to facilitate interdepartmental communication and assure currency of content for policies, procedures, committee pages, schedules and sign-ups, price quotes for materials, etc. Georgia State University even includes "fun pages" for recipes and information on local restaurants. They have included a helpful "wiki posting guidelines and tag list" as an appendix in the article.

Lisa Cotter, et al. (2006, 3-25) addressed usability issues and applied principles of evidence based librarianship to redevelop the Central Coast Health Service Library's intranet site. They provided specific suggestions for usability testing. The use of surveys is discussed in some detail by Robbins (2006, 261-272).

\section{Planning Process}

The library Staff Intranet Team met weekly from March through July 2008. Team membership consisted of representatives from all departments in the library and included professional as well as support staff. One of the team's first activities was a complete review of the contents of the intranet. As mentioned above, the intranet originally housed team and departmental minutes and reports but by early 2008 its usage had greatly expanded to also include the following ColdFusion-scripted applications: documentation for the library's Strategic Plan and the Disaster Plan; training documents for the library's support staff career ladder program; a Web form to record service desk informational transactions; an application to manage author information in the library's institutional repository; a list of online journal subscriptions with accompanying title-level interlibrary loan information; and a library events calendar.

The team brainstormed additional content that was not currently on the intranet but which could improve productivity if it were included. For example, many procedural documents were scattered on several networked drives and individual desktop computers and therefore were not as useful to the staff as they could be. Monthly usage reports of the entire library Web site 
as well as of electronic journals and books had also been developed. These web pages were not linked from the public Web site but also were not part of the intranet. In addition, many photographs had been taken at various library events and then stored on a networked drive. The team believed these images were a valuable part of the library's culture and history and discussed how they might be made more accessible and better organized.

The team recorded all the current and potential content of the intranet and performed an open card-sorting exercise. This exercise yielded seven broad content areas (see Table 1).

\begin{tabular}{|c|c|}
\hline Content Area/Category & Specific Content Included \\
\hline Statistics & $\begin{array}{l}\text { Reports on: e-resource usage, catalog usage, } \\
\text { gate count, service tracking log, month Web } \\
\text { log analyzer }\end{array}$ \\
\hline Staff Personal Profiles & $\begin{array}{l}\text { Form to change password; form to update } \\
\text { profile on the public Web site }\end{array}$ \\
\hline Specific Supporting Applications & $\begin{array}{l}\text { Circulation log "notebook;" service tracking } \\
\text { log; e-journals list with ILL information; } \\
\text { institutional repository name authority } \\
\text { database }\end{array}$ \\
\hline Library History/Archives & $\begin{array}{l}\text { Library photographs and images; past staff } \\
\text { meetings minutes and documents; past team } \\
\text { minutes; past team reports }\end{array}$ \\
\hline Current Awareness & $\begin{array}{l}\text { Events and classes calendar; staff directory; } \\
\text { current staff meeting minutes and documents; } \\
\text { internal library newsletter; current team } \\
\text { minutes }\end{array}$ \\
\hline Staff-Generated Public Content & Web form for staff to author public Web site \\
\hline
\end{tabular}




\begin{tabular}{|l|l|}
\hline & $\begin{array}{l}\text { FAQ; Web site content request form for staff } \\
\text { to initiate Web projects }\end{array}$ \\
\hline Documentation & $\begin{array}{l}\text { Staff meeting instructions; various PDF forms; } \\
\text { library employee handbook; library disaster } \\
\text { plan; intranet instruction manual; service } \\
\text { tracking log; support staff career ladder } \\
\text { program information; strategic planning } \\
\text { documents; circulation log "notebook;" } \\
\text { policies and procedures (including any on } \\
\text { networked drives) }\end{array}$ \\
\hline
\end{tabular}

Table 1. Seven Content Areas from Card Sorting Exercise

The card-sorting exercise and the preceding brainstorming and inventorying activities were done primarily to inform conceptual intranet reorganization efforts. The seven content areas, for example, would not necessarily coincide with specific sections of the intranet.

Next, a number of possible intranet software products were examined to identify the pros, cons, and features of each. Team members had identified several categories of products that could be beneficial for staff productivity, including wiki, blog, discussion forum, and photograph management applications. At this point the team was faced with starting from scratch on the intranet, with the possibility of having to re-tool the existing applications into another scripting language. The other option considered was to keep the existing intranet applications and to find tools written for the current ColdFusion system. Due to the potential time involved in rewriting existing applications, the team chose not to consider re-scripting the existing applications into another language. For this reason the content management system Drupal (http://drupal.org) and the wiki product MediaWiki (http://www.mediawiki.org) were not considered feasible options since they are written in the PHP scripting language. See the "Implementation" section below for more details. 
It was important to assess the level and nature of staff usage of the intranet prior to any redesign efforts. Twenty-four library staff members (out of approximately 40 possible) completed a June 2008 survey on their intranet usage. The survey's purpose was to get an idea of staff members' usage patterns on the intranet and to assess their comfort level with 2.0 tools. The first question asked for the average number of times per week the staff member logged into the intranet. Eleven respondents indicated 1-2 times per week, while ten stated that they logged in at least five times per week. Another question asked the staff if they were currently using any web-based tools such as wikis, blogs, instant messaging, Twitter, photosharing sites, document-sharing sites, social networking sites, tagging/bookmarking sites, or YouTube. Results indicated that, with the exception of Twitter, staff members were quite familiar with these tools.

The next major team activity was a paper prototyping exercise, an important step in the redesign and reorganization of the intranet's user interface. This simple element of "discount usability," popularized by Jakob Nielsen (2009), proved to be a relatively quick, easy, and helpful step in the redesign process. Members worked first individually and then in pairs with chart paper and markers and drew rough sketches of a re-organized intranet home page. They critiqued the schematics and developed a Web model of a new home page, complete with blog postings and a photo of the week. The mockup was shown to key library staff members and was further refined.

\section{Implementation}

The Staff Intranet Team submitted its final report on schedule in August 2008. Library management approved the report, including the proposed model for the reorganization of the intranet. The team was reconvened as the Staff Intranet Implementation Team in September 2008 and was charged with "transitioning the current website to a site that incorporates blogs, wikis, calendar applications, and photo sharing as needed, with the goal of maintaining security and limiting the need for multiple logins" (Lamar Soutter Library, University of Massachusetts Medical School 2009a). Staff convenience necessitated the inclusion of the latter goal related 
to multiple logins. The team's charge specified that the new site should be in production by December 31, 2008.

The avoidance of multiple logins dictated that the team should focus its attention on solutions that would not direct staff members to remote Web sites. This in turn led the team to search for software, preferably freeware, which could be installed on the library's Web server. Since the existing intranet's system was ColdFusion-based, the team focused its search on applications written for that environment. It was also the system with which the library Web manager was most familiar.

Extensive testing of various software tools, which were discussed as part of the previous team's work, was a major component of the implementation team. Four ColdFusion-based tools were all selected from the RIAForge Web site (http://www.riaforge.org), a repository of open source projects built on Adobe technology: Canvas ColdFusion Wiki; BlogCFC; Galleon ColdFusion Forums; and CFCPhotoBlog. Both the wiki and the photo blog require the Model Glue framework, which supports Web application development "by making the construction of Object-Oriented Web and Rich Internet Applications a straightforward process" (Model-Glue Team 2009).

Because these software packages are open source, in several instances the library Web manager was able to extend the functionality of the tools in order to make them more useful to library staff. For example, he added tagging functionality to the photo collection software. This involved both modifications to the ColdFusion templates as well as the addition of two fields to the MYSQL data table. He also added TinyMCE, a Javascript WYSIWYG editor from Moxiecode Systems (http://tinymce.moxiecode.com/), to the blog and the wiki so that staff members would not have to learn blog and wiki rendering syntax. Navigational links back to the intranet home page as well as the inclusion of the intranet banner served to better incorporate the tools into the intranet's overall context.

One disadvantage of open source tools is that the team sometimes felt it was operating in uncharted territory. The library Web manager made several contacts by email and instant 
messaging with the authors of the tools to attempt to resolve issues that arose. The testing of these tools was also an opportunity to begin documenting procedures for future staff training.

Concurrent with the installation and refinement of the software packages was the continued development of the site architecture of the redesigned intranet. Existing pages were converted to the new user interface. Staff members could monitor the progress via a link on the existing intranet home page to the new site. The new site was unveiled in early 2009 (see Figure 1).

A number of ColdFusion elements and capabilities are used to incorporate and automate various features on the home page. The left-hand menu is persistent throughout the intranet and is included by the ColdFusion cfinclude tag, making edits to the menu much easier to implement across all pages. Further, the menu uses the cfmenu tag, which allows styleable dynamic submenus without the need for scripting them in CSS or JavaScript.

The prominent blog section in the center of the home page lists the beginning text of the latest three postings with links to the full entry. They are included on the homepage from the blog's RSS feed. Feed contents are retrieved using the ColdFusion cfhttp tag, and parsed using the xmlparse() function.

The "Wiki Doc of the Day" at the top of the right sidebar is included by a scheduled task in the ColdFusion Administrator. The task is set to run a script that contains the ColdFusion randrange() function to generate a random integer. The random number is used to query the wiki data table to retrieve the corresponding wiki entry, which is then displayed on the intranet home page.

The "Upcoming Events" section is generated from a query of the calendar data table and uses the ColdFusion datecompare() function to display just the events in the next few days. Below that list is a thumbnail version of the full calendar, which uses small red asterisks to link to the information about an event. There is also a link to the full events calendar, which is an application from Advanced ColdFusion Professional Ben Nadel's website (http://www.bennadel.com). 
The photo collection is highlighted by the "Photo of the Week" and is included in a manner similar to the "Wiki Doc of the Day." Each Monday morning a scheduled task selects a new photo and displays it on the home page. A link to the full collection appears under the photo. All ColdFusion database queries on the home page are cached to reduce the number of calls to the database.

The "Today's Hours" feature on the upper right appears on every intranet page. It is included by a ColdFusion Component (CFC) and is mirrored on the library's public website. Extended hours and holiday hours can be specified in an XML script.

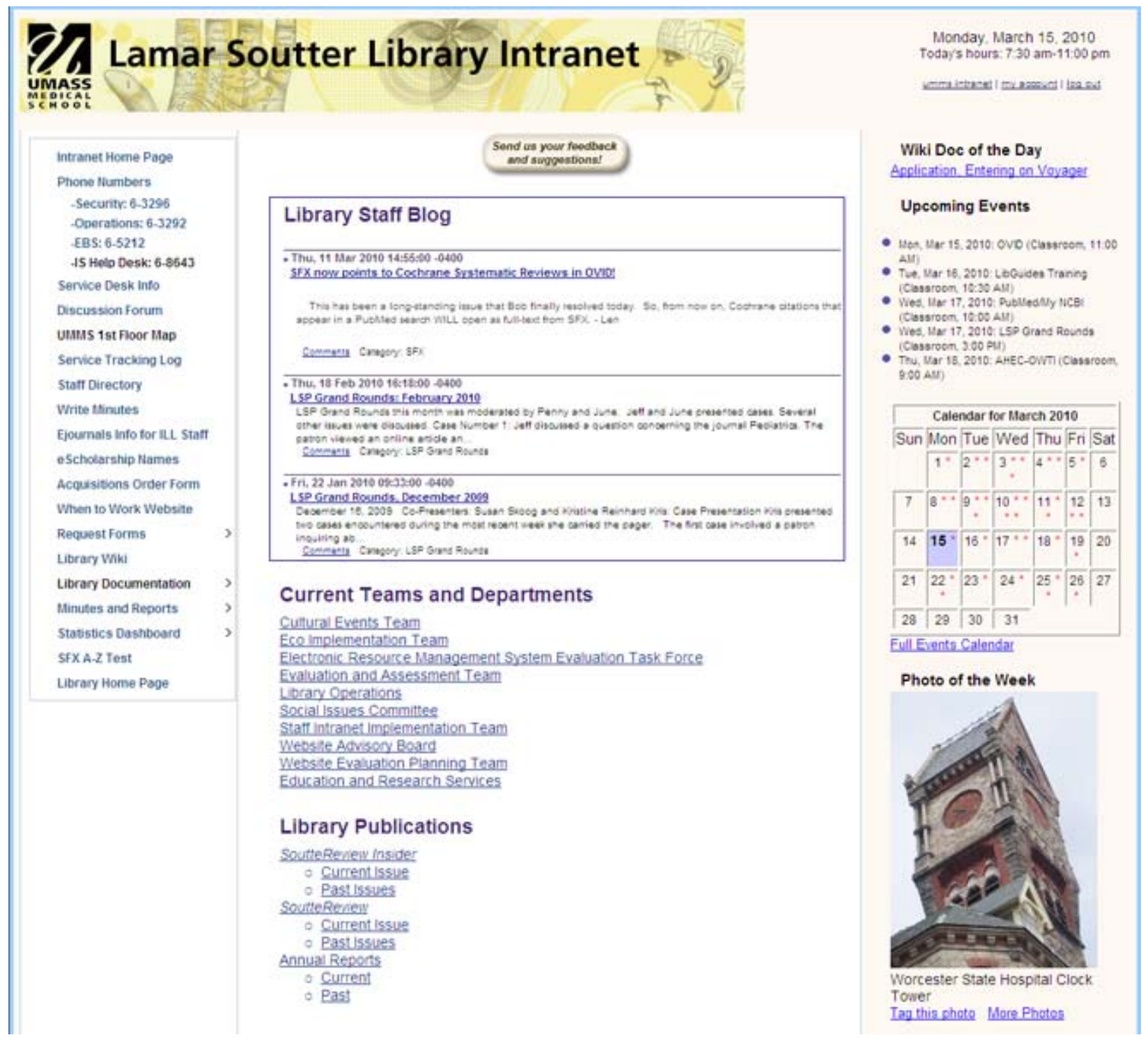


Figure 1. Screenshot of the renovated staff intranet home page

\section{Training and Evaluation}

Since the new interface and specialized tools were not yet available to the library staff, the team felt it was crucial to recommend in its report to library management the formation of a follow-up team to provide training and support. Staff buy-in was considered important for the successful use of the software packages, which could only happen if staff members felt confident enough to incorporate them into their workflow.

In March 2009, the Staff Intranet Implementation Team's term was extended so that it could develop "train the trainer" sessions for selected library staff members. Instruction focused on the four specialized tools listed above. In preparation for the training, a manual for each tool was developed using the wiki and housed there. The team conducted training sessions in late April and early May 2009 for nine library staff members who were designated to train the other staff in their departments.

At about this time the team's life was again extended through December 2009 in order to monitor and evaluate the use of the new tools and the redesigned intranet as a whole. After the initial training was completed the team shifted its focus to gathering feedback from staff on the effectiveness and usefulness of the renovated intranet. Surveys, usability tests, follow-up meetings with the nine staff trainers, and a log of staff-generated errors were all suggested and implemented.

Another survey was sent out in August 2009, and was completed by 24 library staff members (the same return rate as the June 2008 survey). The first question was the same as in the 2008 survey, asking the average number of times per week the staff member logged into the intranet. This time only five respondents chose 1-2 times per week, while sixteen indicated they logged in at least five times per week, suggesting at least a greater interest in the new staff intranet.

The survey also included sections devoted to each of the four software tools, asking questions about how the tool had been used and rating its ease of use. The wiki received the lowest 
average ratings for ease of use of the four applications. Responses for the other tools suggested a lower level of usage than the wiki, as many respondents chose the "N/A" option for many questions related to the blog, discussion forum, and photo collection. The responses to the questions "Please state the reason(s) you don't use the [tool]" indicated that staff members were not using the tools due to lack of time or lack of training, rather than due to technical problems with the respective applications. This supports $O^{\prime}$ Brien and Wisbey's emphasis on the "soft aspect" of the intranet $(2008,29)$. The team followed up with some one-on-one instruction and further discussions with the trainers.

The team also conducted usability testing of the intranet beginning in late August 2009, asking staff members who had undergone training in April and May to participate. The tests were a combination of task performance observation and informal interview. Consistent with the survey results, usability testing indicated that the wiki was again the most difficult tool to use.

Some improvements to the usability of the tools were made based on this testing. In the wiki, for example, navigational enhancements were made and the instruction manual was given more prominence. Also, the "password reminder" feature in the discussion forum was modified to ask for email address rather than username. The library Web manager was able to implement this change after more contact with the forum developer.

\section{Discussion}

Considering the relatively brief period of time that has passed from the first team meeting in March 2008 until the present, team members feel that the newly renovated intranet, with the four tools in place, has already addressed several parts of the library Strategic Plan (Lamar Soutter Library, University of Massachusetts Medical School 2006). Despite some usability issues, the wiki is already serving as a growing "central repository of current and archived library-wide policies and procedures" and is allowing library staff to "actively participate in collaborative efforts." The blog is helping to "communicate to all staff new products and services at the library," while the discussion forum is offering "new ways for staff to provide input on new and/or old services, policies, procedures and how they can be improved." 
A new, more robust calendar application has been incorporated that supports setting meeting recurrence and multiple display options (i.e., day, week, month, and year). The Web manager has added the capability to include meeting room locations, customized the display options to include a printable calendar for posting on the library's computer classroom door, and is currently adding email notification to the appropriate staff when new events are posted. Another desirable feature that has yet to be planned is an intranet-wide search function.

In implementing the software tools some unique challenges had to be overcome. As mentioned above, two of the tools require the Model Glue framework, which also had to be installed on the library Web server. Each tool also has its own authentication system, which had to be either bypassed or modified to alleviate the need for multiple staff logins.

Some tools, such as the blog and the photo collection, were developed as applications for the public internet. As such, the administrative modules are well hidden and secured. In the staff intranet's implementation, however, the team needed to make the admin layer more visible, so links were made that allow all library staff access to upload and manage images and to author blog postings.

Some desired changes to the tools could not be made because doing so would break the entire application. Other modifications sometimes led to loss of native functionality. For instance, the blog in its out-of-the-box configuration supports image uploading into postings. The addition of the TinyMCE toolbar, however, mysteriously deactivated this capability. This problem is still unresolved at this time.

At the time of writing, it may be premature to assess what works well and what is not working as well on the intranet. While the wiki seems to be the source of most troublesome issues, it is also the most-used of the new tools available to staff. To date, there are 285 pages on the intranet wiki. Until other tools begin to be used more frequently, the team may not be able to determine if they too will become problematic.

In retrospect, the team might have been able to achieve better buy-in for the wiki if there had been more time to educate library staff on what a wiki is and how it could be useful for their 
work. Team members were aware of an "experience gap" where some staff members were quite adept at using a certain wiki product such as MediaWiki, Wetpaint, etc., while others had no experience at all with any wiki. More evenly distributed training may have alleviated this situation. Team members have held follow-up training sessions with individual library staff, the effectiveness of which has yet to be evaluated.

Looking ahead, there are some unresolved questions to consider. Is the renovated staff intranet, particularly its new tools, saving staff time and meeting their needs? Who is responsible for promoting usage of the intranet tools? If a tool is getting little usage, does that constitute a failure of the team to accurately appraise the library staff's needs, or does the problem lie with the tool itself? Will future iterations of the intranet necessitate the use of an entirely different platform than ColdFusion?

The team submitted its final report to library management on December 31, 2009, which included recommendations for future oversight and training for the intranet. At this writing library management is considering the next steps for the intranet.

\section{Conclusion}

From the beginning, the library's intranet team considered solutions that would hopefully be a good fit for the library's specific needs. The team had the dual task of redesigning the intranet's outdated user interface as well as considering new tools to include for staff productivity. Given the resources of time, existing technology, and budget available to the team, many decisions had to be made quickly. The question of re-tooling the intranet into another scripting language had to be balanced against the amount of time available. At the same time, the renovated staff intranet has shown potential in furthering some of the goals of the library Strategic Plan.

\section{Acknowledgements}

The authors would like to thank Raymond Camden (author of Canvas ColdFusion Wiki, BlogCFC, and Galleon ColdFusion Forums) and Seth Duffey (author of CFCPhotoBlog) for their assistance in extending the four ColdFusion software applications mentioned in this article. They also 
thank Jane Fama, Associate Director for Library Operations, for her helpful suggestions in preparing this manuscript.

\section{References}

Cotter, Lisa, Larnich Harije, and Suzanne Lewis. 2006. Adding SPICE to a library intranet site: A recipe to enhance usability [computer file]. Evidence Based Library and Information Practice 1, (1): 3-25.

Fichter, Darlene. 2006. Making your intranet live up to its potential. Online (Weston, Conn.) 30, (1) (January/February): 51-3.

- - 2006. Using contextual inquiry to build a better intranet. Online (Weston, Conn.) 30, (5) (September/October): 46-8.

- - 2005. Intranets, wikis, blikis, and collaborative working. Online (Weston, Conn.) 29, (5) (September/October): 47-50.

Fichter, Darlene, and Jeff Wisniewski. 2008. Wiki while you work. Online 32, (3) (May): 55-7.

Glogowski, Joel, and Sarah Steiner. 2008. The life of a wiki: How Georgia State University library's wiki enhances content currency and employee collaboration. Internet Reference Services Quarterly 13, (1) (01): 87-98.

Kennedy, Mary Lee, and Jane Dysart . 2007. Intranets for info pros. Medford, N.J.: Information Today.

Lamar Soutter Library, University of Massachusetts Medical School. Teams, task forces, and committees - staff intranet implementation team. 2009a [cited 10/27/2009]. Available from http://library.umassmed.edu/team_details.cfm?team=staff_intr_impl08 (accessed 10/27/2009).

- - - Teams, task forces, and committees - staff intranet team. 2009b [cited 10/9/2009 2009]. Available from http://library.umassmed.edu/team_details.cfm?team=staff_intr08 (accessed 10/9/2009). 
-- - Strategic plan 2006-2009. 2006 [cited October/9 2009]. Available from http://library.umassmed.edu/strat_plan_apr06.pdf (accessed 10-9-2009).

Langley, Nick. Coldfusion offers a short curve to web development | 12 June 2007 | ComputerWeekly.com. 2007 [cited 10/29/2009]. Available from http://www.computerweekly.com/Articles/2007/06/11/224682/coldfusion-offers-a-shortcurve-to-web-development.htm (accessed 10/29/2009).

Martini, Antonella, Mariano Corso, and Luisa Pellegrini. 2009. An empirical roadmap for intranet evolution. International Journal of Information Management 29, (4) (08): 295-308.

Model-Glue Team. The model-glue framework. 2009 [cited 10/26/2009]. Available from http://www.model-glue.com/ (accessed 10/26/2009).

Nielsen, Jakob. Discount usability: 20 years (Jakob Nielsen's Alertbox). 2009 [cited 10/28/2009]. Available from http://www.useit.com/alertbox/discount-usability.html (accessed 10/28/2009).

OBrien, Mel, and Jillian Wisbey. 2008. Building a dynamic online learning and community environment. Access 22, (3) (September 2008): 29-35.

Robbins, Sarah, Debra Engel, and James Bierman. 2006. Using the library intranet to manage web content. Library Hi Tech 24, (2): 261-72. 